\title{
Genesis and Evolution of Antichromatin Autoantibodies in Murine Lupus Implicates T-dependent Immunization with Self Antigen
}

\author{
Rufus W. Burlingame, Robert L. Rubin, ${ }^{*}$ Robert S. Balderas, and Argyrios N. Theofilopoulos \\ Departments of Immunology and *Molecular and Experimental Medicine, \\ The Research Institute of Scripps Clinic, La Jolla, California 92037
}

\begin{abstract}
Autoantibodies reacting with chromatin and its components, histones and DNA, are characteristic of the human autoimmune diseases SLE and drug-induced lupus, but the mechanisms of their induction remain unknown. Serial serum samples collected over short intervals from lupus-prone MRL/MPlpr/lpr and BXSB mice were tested by ELISA on chromatin and its substructures to characterize the initial autoimmune response to these antigens. Direct binding studies demonstrated that the early autoantibodies recognized discontinuous epitopes on native chromatin and the (H2A-H2B)-DNA subnucleosome. As the immune response progressed, native DNA and other chromatin constituents generally became antigenic. Based on adsorption studies and IgG subclass restriction, antibodies to native DNA were more related to chromatin than to denatured DNA. The kinetics of autoantibody appearance and the Ig class distribution were similar to the kinetics and distribution seen in antibodies induced by immunization with an exogenous T-dependent antigen. These results are most consistent with the view that autoantibodies reacting with chromatin are generated by autoimmunization with chromatin, and antibodies to native DNA are a subset of the wide spectrum of antichromatin autoantibodies. (J. Clin. Invest. 1993. 91:1687-1695.) Key words: antihistone antibodies $\bullet$ anti-DNA antibodies $\bullet$ systemic lupus erythematosus
\end{abstract}

\section{Introduction}

Serum autoantibodies reacting with chromatin and/or its predominant components, histones and DNA, have been found in SLE (1), drug-induced lupus (2), several other human disease states (3), and in murine models of SLE (4-7). The mechanisms causing their initial and continued production are unknown and several theories have been proposed, including direct stimulation of $T$ and $B$ cells by self antigens $(5,8)$, immunization by exogenous mimics $(9,10)$, polyclonal activation (11), and disruption of an idiotypic network (12). Analysis of the fine antigenic specificities and titers of the antichromatin autoantibodies at the onset and during the progression of the autoimmune response could differentiate among the above theories. If the autoimmune response to chromatin mimicked $\mathrm{T}$ -

Address correspondence and reprint requests to Dr. A. N. Theofilopoulos, Department of Immunology-IMM3, The Scripps Research Institute, 10666 N. Torrey Pines Road, La Jolla, CA 92037.

Received for publication 20 July 1992 and in revised form $23 \mathrm{No}$ vember 1992.

J. Clin. Invest.

(C) The American Society for Clinical Investigation, Inc.

$0021-9738 / 93 / 04 / 1687 / 10 \$ 2.00$

Volume 91, April 1993, 1687-1696 dependent immunization, the antibodies should display an IgM to IgG switch, a rapid increase in titer to a number of epitopes on the specific immunogen in relation to other antigens, somatic mutation in complementarity determining regions and affinity maturation. In contrast, with polyclonal activation, a number of different antibody specificities should appear simultaneously and mutations should be random. If autoantibodies result from crossreactive antibodies, then only a single epitope on the self antigen should be recognized, since it is unlikely that an exogenous pathogen would mimic many different parts of a nonhomologous self molecule. An antiidiotypic response is cyclic (13) and is often directed against unrelated antigens because of multiple specificities in parallel sets of idiotypes (14).

For several reasons, antichromatin autoantibodies are a good model system to examine the hypotheses described above. A number of mouse strains with accelerated lupus-like disease develop autoantibodies during a relatively narrow time window (15), allowing investigation of the genesis of autoantibody production, as well as comparison of autoantibody specificities among mouse strains. Additionally, the biochemistry and three-dimensional structure of chromatin and its parts have been extensively studied so that chromatin can be dissected into a limited number of well defined native subnucleosome structures (16-19).

In the present study, the genesis of the immune response to chromatin was studied in MRL/Mp-lpr/lpr (MRL-lpr) ${ }^{1}$ mice of both sexes and BXSB males. Mice were bled at short intervals before and during the time they developed autoantibodies. IgM and IgG antibodies to chromatin, histones, and native, double-stranded DNA (dsDNA) and denatured, singlestranded DNA (ssDNA) were measured in all sera. Selected samples were studied using a wide range of chromatin components, subclass specific detecting reagents, and adsorption with chromatin or DNA. Our results demonstrated that many features of antichromatin autoantibody production resemble those of an active $T$ cell-dependent immunization process, and that autoantibodies recognize a wide spectrum of epitopes on chromatin. Together, these findings imply that chromatin is the structure that initiates the production of antihistone, antisubnucleosome, and anti-dsDNA autoantibodies.

\section{Methods}

Mice. 17 MRL-lpr mice of both sexes and 15 male BXSB mice were obtained from the mouse breeding colony of The Scripps Research Institute ( La Jolla, CA) and kept in a conventional environment. They

1. Abbreviations used in this paper: dsDNA, double-stranded DNA; $\mathrm{MRL} / \mathrm{Mp} /$ lpr/lpr mice, KLH, keyhole limpet hemocyanin; MRL-lpr mice; ssDNA, single-stranded DNA; TI-1, thymus independent class 1; TI-2, thymus independent class 2; TNP-KLH, thymus dependent antigen; TNP-LPS, TI-1 antigen. 
were bled from the retroorbital plexus, and sera were stored at $-20^{\circ} \mathrm{C}$ until use. Initial serial samples from most mice were taken twice weekly starting when they were 7-8 wk old, and after $\sim 1$ mo, each mouse was bled every other week until moribund.

Chromatin, subnucleosomes, histones, and DNA. All procedures for isolating chromatin and histones and reconstituting histone-DNA subnucleosome complexes have been described in detail (20). Briefly, $\mathrm{H} 1$ and histone-histone complexes were prepared from calf thymus (PelFreeze Biologicals, Rogers, $\mathrm{AK}$ ) nuclei by salt extraction at neutral $\mathrm{pH}$ and column chromatography on CM-52 cellulose (Whatman, Maidstone, UK) (16). Histone-DNA subnucleosome complexes were prepared by high to low salt dialysis (21). Individual histones were prepared from the appropriate histone-histone complex by P60 (Bio-Rad Laboratories, Richmond, CA) column chromatography (22). Whole chromatin, H1-stripped chromatin, and trypsinized chromatin were prepared as described $(23,24)$, and the quality of the preparations has been demonstrated previously $(2,20)$. Calf thymus DNA (Calbiochem-Novabiochem Corp., La Jolla, CA ) was further purified by digestion with proteinase $\mathrm{K}$, extraction with phenol, and digestion with $\mathrm{S} 1$ nuclease. ssDNA was prepared by placing DNA in a boiling water bath for $15 \mathrm{~min}$ and cooling on ice.

ELISA. The ELISAs were performed as described (20) with the modification that a precoating with methylated BSA was used when ssDNA as well as dsDNA were the substrates. Briefly, most substrates (see reference 2 for exceptions) were dissolved in PBS at $2.5 \mu \mathrm{g} / \mathrm{ml}$, and $100 \mu$ lof each was added to a microtiter plate (Immulon 2; Dynatech Labs, Inc., Chantilly, VA), incubated overnight, and postcoated for $2 \mathrm{~h}$ with $0.1 \%$ gelatin in PBS. Samples diluted $1: 300$ in serum diluent $(0.1 \%$ gelatin, $0.1 \%$ BSA, $0.075 \%$ bovine gamma globulin, $0.05 \%$ Tween 20 in PBS) were reacted in duplicate for $2 \mathrm{~h}$, washed with PBS$0.05 \%$ Tween, and detected with horseradish peroxidase conjugated goat anti-mouse IgM or IgG (Caltag Labs, South San Francisco, CA), which had been calibrated to yield a similar OD on mouse IgM or IgG coated plates, respectively. To increase the dynamic range of the ELISA, the OD was determined after $10 \mathrm{~min}$ and $60 \mathrm{~min}$, and the data from the latter time point reported. If the OD at $60 \mathrm{~min}$ was greater than the limit of detection of the spectrophotometer (2 OD), the final OD was calculated by extrapolation, which is linear to $\geq 12$ OD (20).

Antisubclass antibodies. The reactivities of subclass-specific detecting reagents (Caltag) were normalized by ELISA against myeloma antibodies of the appropriate IgG subclasses captured by a plate coated with $\left(\mathrm{Fab}^{\prime}\right)_{2}$ goat anti-mouse kappa chain. There was no appreciable cross-reactivity among the IgG subclass specific antibodies. The relative level of the subclasses in each mouse strain was measured from a pool of six sera from 3-mo-old mice. The pooled sera were diluted 1:1,000 in serum diluent, incubated in a plate coated with capturing Ig as above, and detected with the appropriate dilution of subclass-spe- cific detecting reagent. Additionally, the capture assay was used to determine the concentration of IgG2b monoclonal antibodies P4D2 and P17A3 (25). The ODs generated by a dilution of the hybridoma supernatants were compared to a standard curve generated from purified IgG of known concentration.

Solid phase adsorption. Diluted sera were incubated four times for $1 \mathrm{~h}$ each in multiple wells of an ELISA plate coated with the antigen. Controls consisted of sera similarly adsorbed on gelatin-coated wells.

Immunizations. Three mice from each strain were immunized with the thymus-independent class 1 ( TI-1) antigen trinitrophenol-lipopolysaccharide (TNP-LPS) (Sigma Immunochemicals, St. Louis, MO), the thymus-independent class 2 (TI-2) antigen $\mathrm{TNP}_{50}$-Ficoll (Biosearch, San Rafael, CA), or the thymus-dependent antigen $\mathrm{TNP}_{23}-$ keyhole limpet hemocyanin (KLH) prepared as described (26). All mice were boosted 2 wk later with $\mathrm{TNP}_{23}-\mathrm{KLH}$ in incomplete Freund's adjuvant. $\mathrm{TNP}_{11}$-ovalbumin, prepared as described (26), was used as the substrate to detect anti-TNP antibodies.

\section{Results}

Individual mice. The MRL-lpr and BXSB mice were bled at intervals ranging from $3 \mathrm{~d}$ to $2 \mathrm{wk}$ for an average of 10 and 12 samples per mouse, respectively. Initially, all sera were analyzed for IgM and IgG reactivity by ELISA on four substrates: H1-stripped chromatin, in which histone $\mathrm{H} 1$ and most nonhistone proteins had been removed, leaving the core histone octamer wrapped with DNA; the DNA-free (H2A-H2B-H3-H4) histone octamer; dsDNA and ssDNA.

All 17 MRL-lpr mice showed a sustained response ( 2 wk or more) to both IgG antichromatin and anti-ssDNA, and most also had IgM of those specificities ( 16 and 14, respectively). 12 of the mice displayed a sustained IgG anti-dsDNA response. When the data from individual mice were analyzed, two general patterns were observed. IgG antibodies often, but not always, appeared before or concurrently with IgM antibodies of the same specificity, rose sharply to a peak over a 2-3-wk period, and stabilized at a level lower than the peak value. Occasionally, they continued to rise until just before death. Additionally, antichromatin antibodies almost always appeared before or concurrently with antihistone and anti-dsDNA antibodies. However, anti-ssDNA often appeared earlier than antichromatin. As seen in Fig. $1 A$ for MRL-lpr \#6, no IgM autoantibodies were observed until days 92 and 96, when a small transient anti-ssDNA response was seen. In contrast, by days 68 and 72, IgG chromatin and ssDNA antibodies had

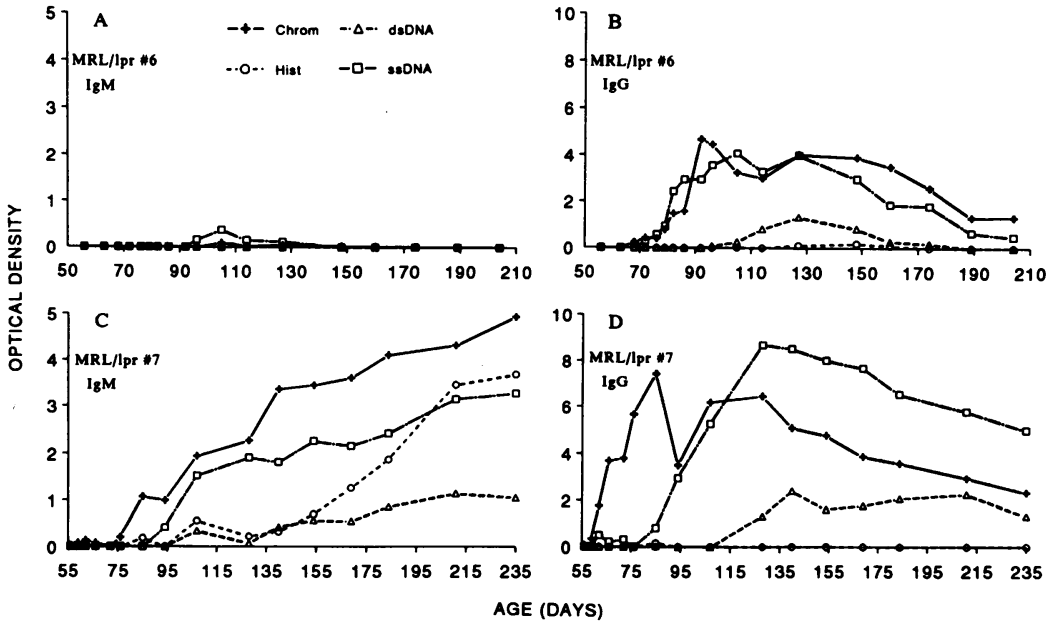

Figure 1. Time course of autoantibody production in individual MRL-lpr mice. IgM $(A)$ and IgG $(B)$ reactivity above normal for MRL-lpr \#6, and IgM $(C)$ and IgG $(D)$ for MRL-lpr \#7. For all substrates, the average $\mathrm{OD}+2 \mathrm{SD}$ of normal mice determined at the same time has been subtracted from the OD of the autoimmune animal to yield OD above normal. Note that both panels displaying IgM reactivity are drawn to the same scale to emphasize the point that the mice make various amounts of these antibodies, but the IgM and IgG scales are different. Chrom, H1stripped chromatin; Hist , (H2A-H2B-H3-H4) ${ }_{2}$ histone octamer. 
already started to rise (Fig. $1 B$ ). They peaked between days 92 and 105 , decreased, and then plateaued until becoming lower in the last month of life. The IgG anti-dsDNA antibodies displayed a lower and later peak while antihistone antibodies were generally absent in this mouse. For MRL-lpr \#7, the IgM antichromatin showed a very small peak at day 63 , and then started to rise steadily at day 76 (Fig. $1 C$ ). Antibodies to the other three antigens started to rise on days 85-105. However, the IgG antichromatin response started rising sharply at day 59 , peaking by day 85 , and then decreasing (Fig. $1 D$ ). There was a small early ssDNA response, which increased rapidly from day 85 to 128 . Interestingly, IgG anti-dsDNA antibodies did not rise until day 128 , after the IgM anti-dsDNA. Fig. 1, $A-D$ are typical for the majority of MRL-lpr mice. When the 12 mice with a sustained IgG anti-dsDNA response are considered, IgG antichromatin appeared earlier or at the same time as anti-dsDNA in all of them. IgG was detected earlier or at the same time as IgM of the same specificity in 8 of these 12 mice.

Analysis of all bleeds in each mouse by linear regression revealed that changes in IgG chromatin and ssDNA antibodies were related within individual mice (average $r=0.79$ for all 17 mice). No other average correlation $>0.7$ was found when all combinations of IgG and IgM reactivities were compared. The first antibody appearing was usually IgG anti-ssDNA ( 7 of 17), IgG antichromatin, or IgM anti-ssDNA (four each).

For the BXSB mice, the first antibody to appear was usually IgG antichromatin ( 7 of 15), IgG anti-ssDNA (4 of 15), or IgM anti-histone ( 3 of 15 ). All mice displayed a sustained IgG response to chromatin and ssDNA, and 10 to dsDNA. Interestingly, the IgM responses to these four antigens were closely related. This point is emphasized in Fig. $2 \mathrm{~A}$, which shows that BXSB \#4 had a late IgM response starting between days 115 and 150, and in Fig. $2 C$, where BXSB \#12 had an early one starting around day 50 . However, in both these mice, the IgG antibodies arose earlier than or concurrently with IgM and did not all change together. Fig. $2 B$ demonstrates that IgG antibodies reactive with ssDNA, chromatin, and histones, all clearly arose before the corresponding IgM and changed titers independently. For BXSB \#12 (Fig. $2 D$ ), there was an early IgG antichromatin reaction, and the other three IgG specificities arose concomitantly with the corresponding IgM.

Linear regression analysis of the IgM data of individual BXSB mice confirmed that these antibodies were indeed linked. The average $r$ value varied from 0.78 to 0.88 when each pair of substrates was compared: the lowest was ssDNA compared with histone, and the highest was ssDNA compared with chromatin, and the average standard deviations of the $r$ values were small $(0.14-0.26)$. The only other correlation $>0.7$ was IgM vs. IgG antibodies for ssDNA $(r=0.78)$. When just antichromatin and anti-dsDNA are considered in the 10 mice with a sustained IgG anti-dsDNA response, IgG antichromatin arose before or concurrently with IgG anti-dsDNA in all of the mice. Also, IgG arose earlier or at the same time as the corresponding IgM reactivity in all of these 10 mice.

Average autoantibody appearance. Fig. $3 \mathrm{~A}$ shows the biweekly average and standard deviation of $\operatorname{IgM}$ reactivities of all tested MRL-lpr mice on the four substrates. The average antichromatin response rose steadily from 8 to $20 \mathrm{wk}$ before dropping at the last time point, while antihistone and antissDNA remained relatively low from 8 to $14 \mathrm{wk}$, and then gradually increased. IgM anti-dsDNA remained low, except for a transient increase at $16 \mathrm{wk}$. At all time points, the average IgM reactivity was highest for chromatin and second highest for ssDNA. The IgG reactivity displayed a different pattern (Fig. $3 \mathrm{~B}$ ). Anti-ssDNA antibodies predominated, with antichromatin second highest, and both antibody levels increased steadily to high levels from 8 to $20 \mathrm{wk}$. The IgG anti-dsDNA reactivity did not rise much above background level until 18 wk, and then stayed elevated. In contrast, the IgG antihistone antibodies displayed a fairly constant low level of reactivity. The large mouse to mouse variability resulted in high standard deviations for all antigens in both IgM and IgG.

In the BXSB mice, the average IgM reactivities to all four substrates changed concordantly (Fig. $3 C$ ). The high standard deviations are present because different mice started their IgM autoantibody responses at different ages, and the absolute amount of antibody varied among mice, but once an individual started an IgM response, antibodies to all four substrates rose concomitantly and to a similar extent, as seen above. Their IgG response to the four antigens sometimes started before $8 \mathrm{wk}$ of age, antichromatin generally dominated the early response and anti-ssDNA arose later, also to high levels (Fig. 3 $D$ ). Antihistone antibodies displayed a higher level of binding and appeared earlier than anti-dsDNA antibodies.

In both strains, the appearance of IgG before IgM of the same specificity is not seen as clearly in the averages as in the

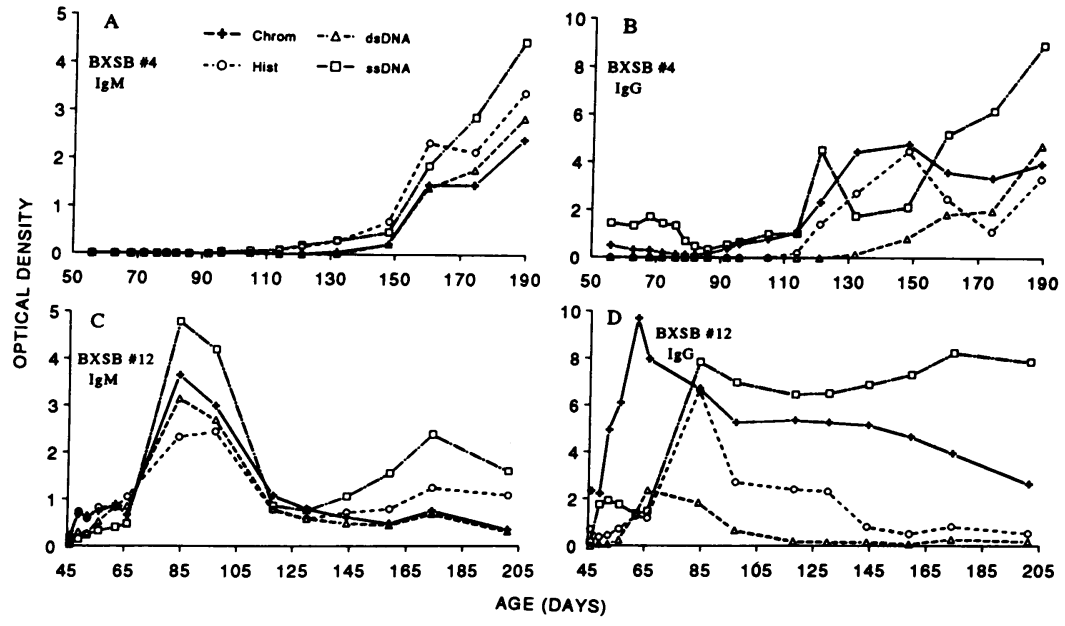

Figure 2. Time course of autoantibody production for individual BXSB mice. $\operatorname{IgM}(A)$ and $\operatorname{IgG}(B)$ reactivity above normal for BXSB \#4, and IgM $(C)$ and IgG $(D)$ for BXSB \#12. The scales and the abbreviations for the substrates are the same as in Fig. 1. 


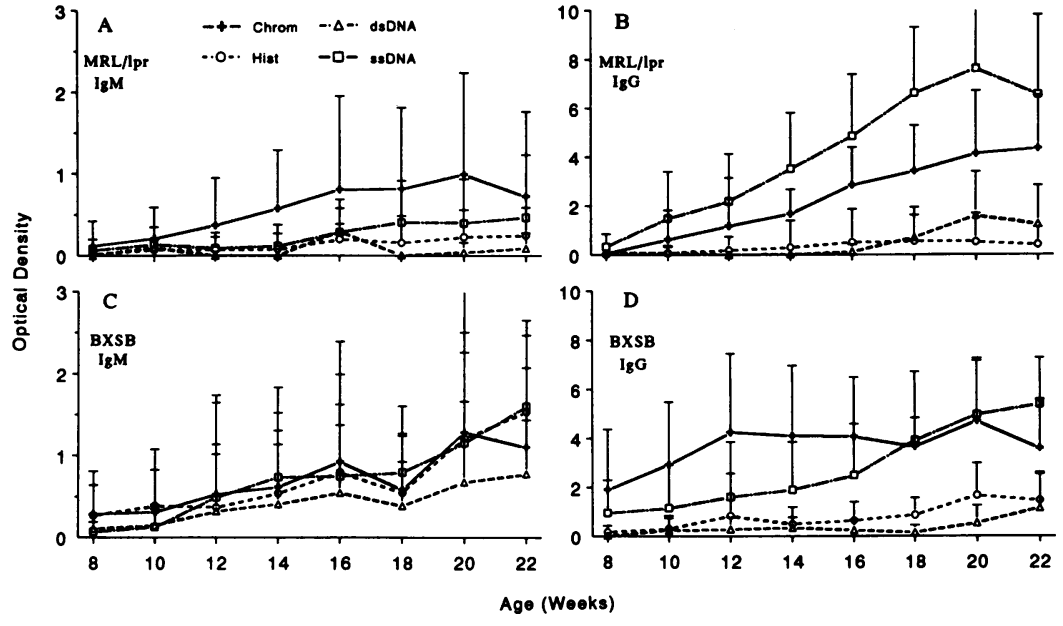

Figure 3. Time course of average autoantibody production in mice measured by ELISA. The graphs depict the average $\mathrm{OD}(+\mathrm{SD})$ above normal for four substrates. For the MRL-lpr strain ( $A$ and $B$ ), the data from 17 mice were averaged at the 8 -wk time point and nine were alive at $22 \mathrm{wk}$. For male BXSB mice $(C$ and $D)$, the data from 15 mice were averaged for the 8-wk time point and seven mice were alive at 22 wk. Note that $\operatorname{IgM}(A$ and $C)$ and $\operatorname{IgG}(B$ and $D)$ are drawn to different scales. The abbreviations for the substrates are the same as Fig. 1. At a 95\% confidence level using a two-tailed $t$ test, the average IgM antichromatin level of MRL-lpr mice was significantly elevated compared to the IgM anti-dsDNA for weeks 10-20, and was different than all other reactivities only on week 14. For the MRL-lpr IgG binding, average antichromatin and anti-ssDNA levels were significantly elevated compared to the other two substrates from weeks 12 to 22 . In the BXSB mice, there were no significant differences among the average reactivities of the IgM antibodies at all time points. In contrast, the average level of IgG antichromatin was significantly elevated compared to either IgG anti-dsDNA or antihistone reactivities at all times, as well as the IgG anti-ssDNA from weeks 10 to 14 .

analysis of individual mice because some mice were early for both antibody classes, obscuring the individual patterns. The clear IgG response to chromatin before IgG to dsDNA and histones is less distinct in the averages for the same reason. Even with the high standard deviations, there were still significant differences between average reactivities as noted in the legend to Fig. 3.

Age at first appearance of autoantibodies. For the $12 \mathrm{MRL}-$ $l p r$ mice that had a sustained IgG anti-dsDNA response, Fig. 4 $A$ displays the age at which their IgG antichromatin and IgG anti-dsDNA first appeared. In the graph, $8 \mathrm{C}$ is placed over the age that mouse number 8 first displayed its IgG antichromatin (between 7 and $8 \mathrm{wk}$ ), and $8 D$ is placed over the age that this

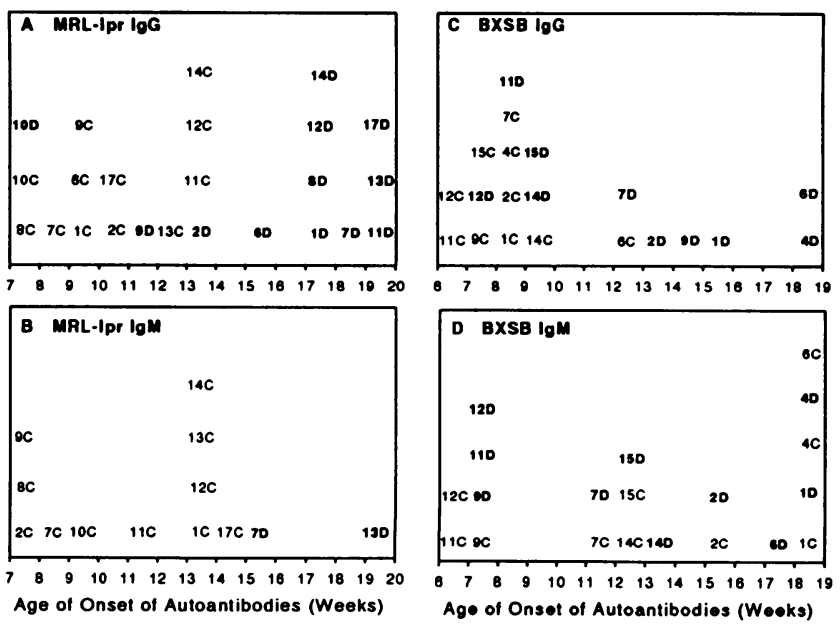

Figure 4. Age of onset of antichromatin and anti-dsDNA autoantibodies. Each mouse is represented by its number followed by $D$ for anti-dsDNA and $C$ for antichromatin. This symbol is placed above the age that anti-dsDNA or antichromatin first appeared. The symbols for anti-dsDNA reactivity are in bold to help distinguish them from the markers for antichromatin reactivity. $A(\operatorname{IgG})$ and $B(\mathrm{IgM})$ display the $12 \mathrm{MRL}-l p r$ mice with a sustained ( $\geq 2 \mathrm{wk}$ ) anti-dsDNA response, while $C(\operatorname{IgG})$ and $D(\operatorname{IgM})$ show the $10 \mathrm{BXSB}$ mice with a sustained IgG anti-dsDNA response. mouse started its IgG anti-dsDNA response (between 17 and 18 wk). Most mice first displayed antichromatin between 7 and 14 wk of age, while the anti-dsDNA usually developed between 11 and $20 \mathrm{wk}$. Interestingly, the three mice with the earliest anti-dsDNA response, numbers 10,9, and 2, also had relatively early anti-chromatin responses. For these same 12 mice, the age at first occurrence of IgM antibodies with these specificities is displayed underneath in Fig. $4 \mathrm{~B}$. Most did not show IgM anti-dsDNA antibodies, but of the two that did, IgM antichromatin was earlier. Compared with IgG depicted in the figure above, IgM anti-dsDNA for number 7 appeared earlier than the corresponding IgG response, and for number 13, the same time as the corresponding IgG response. For IgM antichromatin, numbers 2,9 , and 11 appeared earlier than the corresponding IgG; numbers $8,7,12$, and 14 appeared at the same time; and the other mice displayed IgM after the corresponding IgG.

Fig. $4 C$ shows that of the $10 \mathrm{BXSB}$ mice with a sustained IgG anti-dsDNA response, all except number 14 showed an earlier IgG antichromatin response. For mouse number 14, the two reactivities arose simultaneously. The mice that developed anti-dsDNA antibodies early in life showed antichromatin even earlier. The age distribution of the appearance of IgM reactivity in the BXSB mice is striking (Fig. $4 D$ ). In each of the 10 mice depicted, IgM antichromatin and IgM anti-dsDNA appeared at the same time or within 1 wk of each other. When compared to the appearance of antichromatin IgG, BXSB numbers 11,12 , and 9 displayed IgM antichromatin at the same time, while the other seven mice displayed IgG first. This figure emphasizes the point mentioned earlier that the IgM reactivities to these substrates rose and fell together, but independent of the IgG.

Reactivity with subnucleosomes and individual histones. The results from the serial bleeds suggested that autoantibodies recognized a number of different epitopes on chromatin. To examine this possibility more fully, sera from six mice of each strain were chosen at a time before they developed anti-dsDNA antibodies, so that reactivity with DNA-containing substrates could not be caused by the presence of anti-dsDNA antibodies. They were analyzed on a set of substrates that represented all 
the native substructures of chromatin that can be isolated at neutral $\mathrm{pH}$, as well as the individual histones separated from each other in dilute acid. The IgM antibodies from five of six MRL-lpr mice (Fig. $5 \mathrm{~A}$ ) bound strongly to the three most native substrates, whole chromatin, $\mathrm{H} 1$-stripped chromatin and trypsinized chromatin (in which $\sim 15 \%$ of the $\mathrm{NH}_{2}$-terminal residues of all histones and some $\mathrm{COOH}$-terminal residues of $\mathrm{H} 2 \mathrm{~A}$ and $\mathrm{H} 3$ are removed). They also bound to the (H2AH2B) dimer-DNA complex. Four of the samples showed very low reactivity with the $(\mathrm{H} 3-\mathrm{H} 4)_{2}$ tetramer-DNA complex, while none bound to $\mathrm{H} 2 \mathrm{~A}, \mathrm{H} 3, \mathrm{H} 4$, or the $(\mathrm{H} 3-\mathrm{H} 4)_{2}$ tetramer. Serum number 4 recognized $\mathrm{H} 2 \mathrm{~B}$ and the $\mathrm{H} 2 \mathrm{~A}-\mathrm{H} 2 \mathrm{~B}$ dimer, while serum number 6 bound to H1, H1-DNA, H2B, and H2A-H2B. For IgG antibodies, all six sera displayed binding to the three forms of chromatin (Fig. $5 B$ ). Five out of six sera also recognized the (H2A-H2B)-DNA complex, even though four of these did not bind to DNA-free $\mathrm{H} 2 \mathrm{~A}-\mathrm{H} 2 \mathrm{~B}$. These five sera also bound to H1-DNA, albeit very weakly. The (H3-H4) ${ }_{2}$ tetramer, both free from and complexed with DNA, was largely nonreactive. The sera showed variable binding with individual histones. None reacted with $\mathrm{H} 4$; sera numbers 1 and 4 bound weakly to $\mathrm{H} 2 \mathrm{~B}$ and $\mathrm{H1}$; and serum number 5 bound strongly to $\mathrm{H} 2 \mathrm{~A}, \mathrm{H} 2 \mathrm{~B}$, and $\mathrm{H} 1$, and weakly to $\mathrm{H} 3$.

For BXSB mice the predominant IgM reactivities were not always with the most native antigens (Fig. $5 C$ ). Even though five sera reacted with the chromatin substrates, these were the most reactive substrates for only three of them. H1 was most antigenic for the other three sera, while $\mathrm{H} 2 \mathrm{~A}, \mathrm{H} 2 \mathrm{~B}, \mathrm{H} 3$, and $(\mathrm{H} 3-\mathrm{H} 4)_{2}$ were also reactive. In contrast, $\mathrm{IgG}$ from $\mathrm{BXSB}$ mice without antibodies to dsDNA reacted most strongly with the native substrates whole chromatin, $\mathrm{H} 1$-stripped chromatin and trypsinized chromatin, and the subnucleosome structure (H2A-H2B)-DNA (Fig. $5 \mathrm{D}$ ). The other subnucleosome structures, $(\mathrm{H} 3-\mathrm{H} 4)_{2}$-DNA and $\mathrm{H} 1$-DNA, were much less reactive or unreactive. These sera displayed a wide reactivity with individual histones. Five bound above normal to $\mathrm{H} 2 \mathrm{~A}$ and/or $\mathrm{H} 2 \mathrm{~B}$, four to $\mathrm{H} 3$ and/or $\mathrm{H} 4$, and four to $\mathrm{H} 1$.

To further examine relative antigen accessibility on the ELISA plate, binding by monoclonal antibodies with different specificities was examined. $0.1 \mu \mathrm{g} / \mathrm{ml}$ of P4D2, an IgG2b that binds H2B (25), and $0.1 \mu \mathrm{g} / \mathrm{ml} \mathrm{P17A3}$, an IgG2b that binds dsDNA (25), were reacted on H2B and dsDNA. P4D2 yielded an OD of 3.78 on $\mathrm{H} 2 \mathrm{~B}$ and that of P17A3 was 3.39 on dsDNA. To further characterize the DNA-containing substrates, five other anti-dsDNA monoclonal antibodies were reacted with dsDNA, ssDNA, and H1-stripped chromatin. Normalized to dsDNA, the five antibodies reacted an average of $89.5 \% \pm 4.6 \%$ as much with ssDNA and $97.0 \% \pm 3.8 \%$ as much with $\mathrm{H1}$ stripped chromatin. Thus, identical concentrations of different antibodies yield similar ODs on different substrates. This substantiates the validity of comparing antibody reactivities on different substrates.

Relationships among antibodies to DNA-containing antigens. In MRL-lpr mice, there was a strong statistical correlation between the appearance of antichromatin and anti-ssDNA antibodies. In addition, we thought that these two populations could be related, since chromatin contains regions of DNA sensitive to the enzyme $S 1$ nuclease that recognizes ssDNA but not dsDNA (27) and antibodies crossreactive with ssDNA and chromatin have been reported (28). However, in five sera without anti-dsDNA antibodies, adsorption with chromatin in solution could only remove $4 \% \pm 7 \%$ of the ssDNA reactive antibodies. Surprisingly, ssDNA in solution inhibited $46 \% \pm 21 \%$ of the chromatin binding. However, reduction in binding to chromatin after addition of ssDNA was probably the result of blocking epitopes on chromatin by binding of ssDNA to the solid-phase antigen, as previously reported for the inhibition of anti-(H2A-H2B)-DNA by ssDNA (29). Thus, these data indicate that antichromatin and anti-ssDNA are predominantly separate antibody populations.

A provocative finding that can be seen directly in Figs. 1 and 2 and inferred from Figs. 3 and 4 is that $\operatorname{IgG}$ anti-dsDNA antibodies invariably appeared after both anti-ssDNA and antichromatin antibodies were already present. Since dsDNA is a component of chromatin and also shares some epitopes with ssDNA (30), we wanted to determine if anti-dsDNA antibodies were more related to antichromatin or anti-ssDNA antibodies. Two approaches were taken to examine the interrelatedness of these three antibody populations. First, sera containing anti-dsDNA antibodies were adsorbed by solid-phase ssDNA

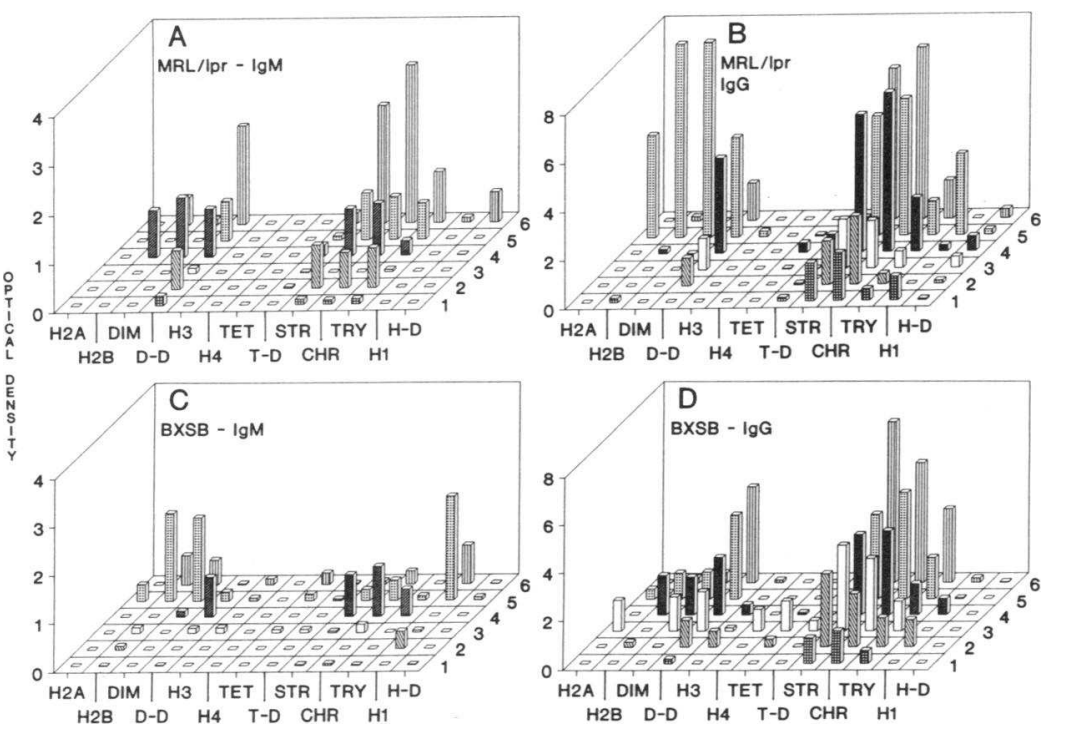

Figure 5. Autoantibodies to chromatin components in mice without anti-dsDNA antibodies. Specific samples were chosen from six MRL-lpr $(A$ and $B)$ and six BXSB ( $C$ and $D$ ) mice at a time before they developed anti-dsDNA antibodies so that reactivity with DNA-containing substrates can not be attributed to the presence of anti-DNA antibodies. Each of the six horizontal rows displays the reactivity of one mouse on the 13 substrates. IgM ( $A$ and $C$ ) and $\operatorname{IgG}$ ( $B$ and $D$ ) antibody reactivities are drawn to different scales. $H 2 A$, denatured $\mathrm{H} 2 \mathrm{~A} ; H 2 B$, denatured $\mathrm{H} 2 \mathrm{~B} ; D I M$, native H2A-H2B dimer; $D-D$, (H2A-H2B) dimerDNA subnucleosome complex; $H 3$, denatured $\mathrm{H} 3$; $H 4$, denatured $\mathrm{H} 4$; $T E T$, native $(\mathrm{H} 3-\mathrm{H} 4)_{2}$ tetramer; $T$ - D, ( $\mathrm{H} 3-\mathrm{H} 4)_{2}$ tetramer-DNA subnucleosome complex; STR, H1-stripped chromatin; $C H R$, whole chromatin; $T R Y$, trypsinized H1-stripped chromatin; $H 1$, salt extracted $\mathrm{H} 1$; and $H-D, \mathrm{H} 1-\mathrm{DNA}$ subnucleosome complex. 
Table I. Adsorption with Solid-phase ssDNA

\begin{tabular}{lccr}
\hline & \multicolumn{3}{c}{ Antibody activity removed (percent decrease) } \\
\cline { 2 - 4 } \multicolumn{1}{c}{ Mouse } & ssDNA & dsDNA & Chromatin \\
\hline MRL/lpr \#4 & $84 \%$ & $8 \%$ & $15 \%$ \\
MRL/lpr \#6 & $91 \%$ & $0 \%$ & $21 \%$ \\
MRL/lpr \#8 & $96 \%$ & $30 \%$ & $6 \%$ \\
MRL/lpr \#14 & $95 \%$ & $62 \%$ & $38 \%$ \\
MRL/lpr \#14 & $88 \%$ & $56 \%$ & $56 \%$ \\
Monoclonal 1D12 & $100 \%$ & $98 \%$ & $99 \%$ \\
\hline
\end{tabular}

* Sera containing anti-dsDNA antibodies were adsorbed on solid phase ssDNA or gelatin and ELISA performed on the indicated substrates. ${ }^{\ddagger}$ Samples from the same animal taken 3 mo apart. ${ }^{\S}$ This monoclonal antibody binds to nearly the same extent with dsDNA, ssDNA, and chromatin (20).

and tested on the three substrates. Table I shows that this treatment adsorbed an average of $91 \%$ of the anti-ssDNA reactivity, but only an average of $31 \%$ of the anti-dsDNA reactivity and $27 \%$ of the antichromatin reactivity. Thus, the bulk of the antidsDNA antibodies did not recognize epitopes present on ssDNA. It should be pointed out that ssDNA in solution adsorbed an average of $93 \%$ of the dsDNA reactivity (not shown). Presumably, liquid phase ssDNA has more flexibility to assume base-stacking conformations than does solid-phasebound ssDNA, or there could be antibody-induced renaturation of ssDNA in solution.

In the second approach, the IgG subclass distribution of these autoantibodies was measured early, middle, and late in the autoimmune response from six mice of each strain. For MRL-lpr mice, chromatin and dsDNA reactive antibodies were somewhat restricted in that IgG2a predominated, IgG1 and $\mathrm{IgG} 2 \mathrm{~b}$ were present occasionally, and $\mathrm{IgG} 3$ reactivity was rare. The ssDNA response was more promiscuous in that most animals had reactive antibodies of all four IgG subclasses with IgG3 and $\operatorname{IgG} 2$ a predominating and $\operatorname{IgG} 1$ the least reactive. Fig. $6, A$ and $B$ show representative individuals. The relative predominance of the anti-ssDNA antibodies is similar to that of antigen-nonspecific Ig found in pooled MRL-lpr sera ( IgG3 $=37 \%, \operatorname{IgG} 2 \mathrm{a}=36 \%, \operatorname{IgG} 2 \mathrm{~b}=16 \%$, and $\operatorname{IgG} 1=11 \%)$. In contrast, the relative predominance of subclasses in the antichromatin and anti-dsDNA antibodies is similar to that induced in vitro by supernatants of cultured MRL-lpr double negative $\mathrm{T}$ cells, where IgG2a was most induced and IgG3 the least (31).

For BXSB mice, reactivity with all three substrates was usually IgG2b, sometimes IgG2a, and rarely IgG1 or IgG3 (Fig. $6, C$ and $D$ ). This is somewhat different than the relative predominance found in total Ig from pooled sera where IgG3 was the major subclass $(\operatorname{IgG} 3=43 \%, \operatorname{IgG} 2 b=32 \%, \operatorname{IgG} 2 a=18 \%$, and IgG $1=7 \%$ ). In Fig. $6 \mathrm{D}$, it can be seen that the predominant antichromatin response switched from IgG1 to IgG2b late in this individual's disease. No mouse made anti-dsDNA without anti-ssDNA and antichromatin antibodies of the same subclass.

Adsorption with chromatin or dsDNA. Analysis of the binding specificities from serial serum samples revealed that like the anti-dsDNA reactivity, binding to H1-DNA and tetramerDNA also increased late in life (not shown). To determine if the rise in reactivity to ( $\mathrm{H} 3-\mathrm{H} 4)_{2}$-DNA was simply caused by the DNA component of this antigen or if a separate population of antibodies with specificity for the ( $\mathrm{H} 3-\mathrm{H} 4)_{2}$-DNA complex arose concomitantly with antibodies to dsDNA, sera with antidsDNA reactivity were tested on tetramer DNA before and after adsorption with dsDNA or stripped chromatin. As seen in Fig. $7,1-2 \mu \mathrm{g}$ of chromatin removed $\sim 75 \%$ of the tetramer DNA reactivity for both strains and $32 \mu \mathrm{g}$ removed virtually $100 \%$. In contrast, even after treatment with $32 \mu \mathrm{g}$ DNA, an average of $20 \%$ of the anti-tetramer DNA remained in MRLlpr mice (Fig. $7 \mathrm{~A}$ ) and $50 \%$ in BXSB mice (Fig. $7 \mathrm{~B}$ ). Thus, unique epitopes on the (H3-H4) $)_{2}$-DNA complex became antigenic as the immune response progressed, particularly in the BXSB strain.

Immunizations with TI-1, TI-2, and TD antigens. To compare the kinetics of appearance of autoantibodies with those of antibodies produced by immunization, 10-wk-old mice were immunized with various forms of TNP. In all three types of immunization, BALB/c (shown) and C57BI/6 mice (not shown) were virtually identical. As seen in Fig. 8, $A$ and $B$, immunization with the TI-1 antigen TNP-LPS caused a sharp IgM response on day 4 , followed $2 \mathrm{~d}$ later by a lesser increase in IgG in both BALB/c and MRL-lpr strains. All three BXSB mice injected with $100 \mu \mathrm{g}$ TNP-LPS died 2-3 d after injection, perhaps because of stimulation of the large number of monocytes that these lupus mice contain (4). For the BALB/c mice,

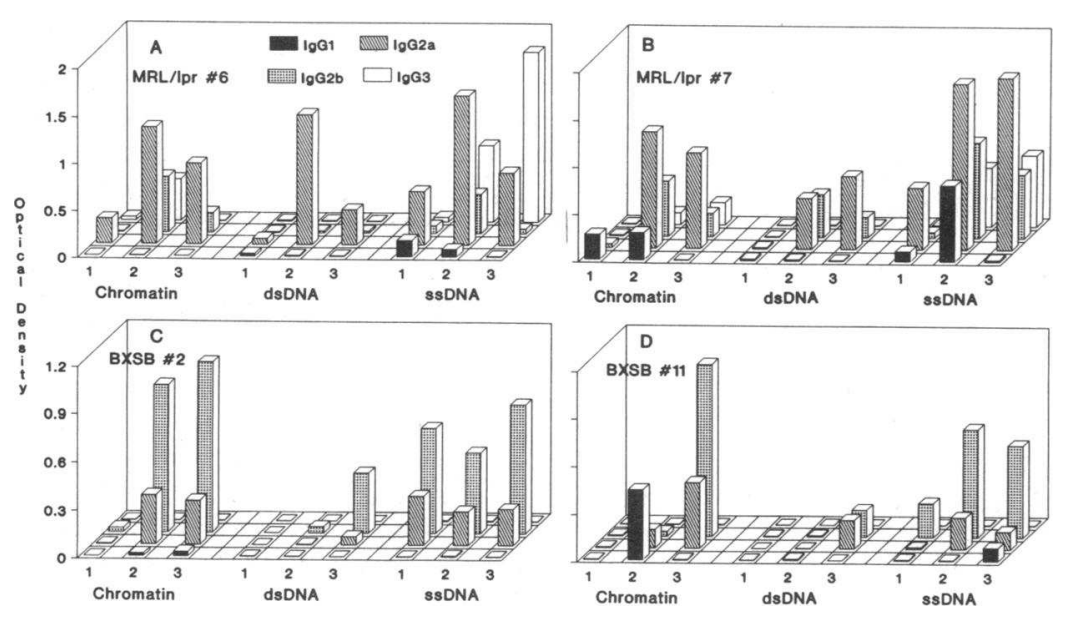

Figure 6. IgG subclasses of autoantibodies. Subclass specific reactivity with chromatin, dsDNA, and ssDNA were determined at three time points: early, middle, and late in the course of the animal's disease. 1,2 , and 3 along the $x$ axis refer to the serial bleeds, and the ELISA substrates are placed with chromatin on the left, dsDNA in the middle and ssDNA on the right. The horizontal rows display subclass specific reactivity with IgG1 in the front and IgG3 in the back. $A$ and $B(M R L-l p r)$ are drawn to a different scale than $C$ and $D(B X S B)$. 


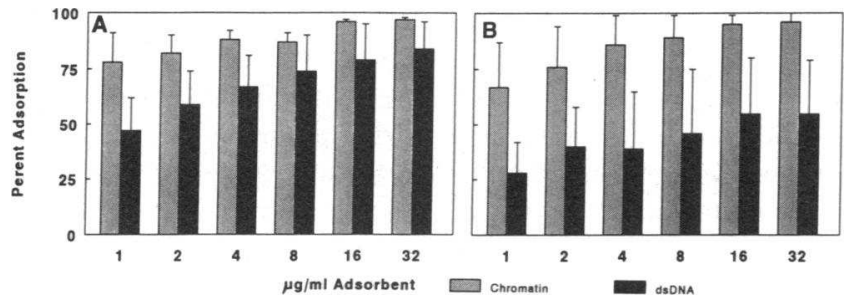

Figure 7. Absorption of ( $\mathrm{H} 3-\mathrm{H} 4)_{2}$-DNA reactivity by liquid phase H1-stripped chromatin and dsDNA. Immunoabsorbent at the indicated concentrations was added to sera, incubated for $2 \mathrm{~h}$ at room temperature, and then ELISA performed as usual. The averages and SD for six MRL-lpr (A) and six BXSB (B) mice are displayed. As a measure of nonspecific absorption, at $4 \mu \mathrm{g} / \mathrm{ml}$ of chromatin the antiTNP reactivity in control mice was decreased $14 \% \pm 13 \%$.

the IgG response to the TI-2 antigen $\mathrm{TNP}_{50}$-Ficoll (Fig. $8 C$ ) was lower than that induced by TNP-LPS. However, both autoimmune strains had a larger and earlier $\mathrm{IgG}$ reaction than the normal mice, and the BXSB mice displayed a much lower IgM titer than the other strains (Fig. 8, $D$ and $E$ ). Perhaps the monocytosis in the BXSB strain caused a rapid IgM to IgG switch, accounting for the low IgM observed. For both TI-1 and TI-2 immunization protocols the BALB/c mice showed a sharp rise in IgG after $18 \mathrm{~d}$, presumably because of the $\mathrm{TNP}_{23}-\mathrm{KLH}$ boost given on day 14. This immunization protocol measures the ability of a T-dependent antigen to further stimulate B cells in the absence of memory $T$ cells, and might have induced an isotype switch in the previously activated B cells. The MRL-lpr and BXSB mice did not display this characteristic, presumably because the switch to IgG had already occurred. However, as expected with the T-dependent antigen $\mathrm{TNP}_{23}-\mathrm{KLH}$, the normal and autoimmune groups (Fig. 8, $F-H$ ) displayed a typical IgG response that rose gradually from days 7-14 and increased sharply after the boost. Interestingly, IgM antibodies in mice primed and boosted with the T-dependent antigen were barely detectable, suggesting a very rapid IgM to IgG switch.

\section{Discussion}

The genesis and evolution of autoantibodies reactive with chromatin and its components have been determined to gain insight into the immunologic processes that produced them. Serial serum samples were obtained at short time intervals from MRL-lpr and BXSB mice, tested on many related antigens, and relationships among antibody populations were examined by adsorption studies. Despite being inbred, these mice displayed large differences in the age of onset, titer, and fine specificity of their antichromatin responses, consistent with the view that stochastic processes played a role in the production of these autoantibodies (32). However, in both strains of mice, IgG antibodies reactive to chromatin and ssDNA were found in high titer in every individual, indicating that there was a similar immunologic process occurring in each of the mice. Their initial autoimmune response was primarily directed against conformational epitopes on native chromatin and the (H2A-H2B)-DNA subnucleosome. Antibodies to other subnucleosome structures and individual histones were present in lower titer and arose later in the course of disease. The rapid rise of IgG autoantibodies over a few days to a few weeks, the predominance of IgG over IgM, and the use of the IgG2a and IgG2b subclasses were similar to the kinetics, class, and subclass preference (33) of antibodies induced by immunization with a T-dependent protein antigen or a virus, but not a carbohydrate antigen. Taken together, these data are most consistent with the concept that autoantibodies reactive with chromatin were caused by $\mathrm{T}$-dependent immunization with chromatin.

What could cause the variability in both the time of appearance and the fine specificity of the autoantibodies in inbred mice? The random combinatorial events and somatic mutations that occur in the formation of immunoglobulins (34), and similar processes that take place in the successful expression of the $\mathrm{T}$ cell receptor ( 35 ) produce animals that have genetically different antigen-responsive cells even though their genomic DNA is identical. Thus, divergence among inbred mice in the initial specificity of antigen-responsive cells would add to the diversity of their autoimmune responses. Differences in the precursor frequency of anti-Sm antibodies have been found in MRL-lpr mice (32). Another factor that could cause variation is the putative immunization event. If at least two unlinked processes had to occur to produce autoantibodies, then the probability of two independent events occurring simultaneously in the same place could contribute to the variability in age of onset of autoantibody production (see below).

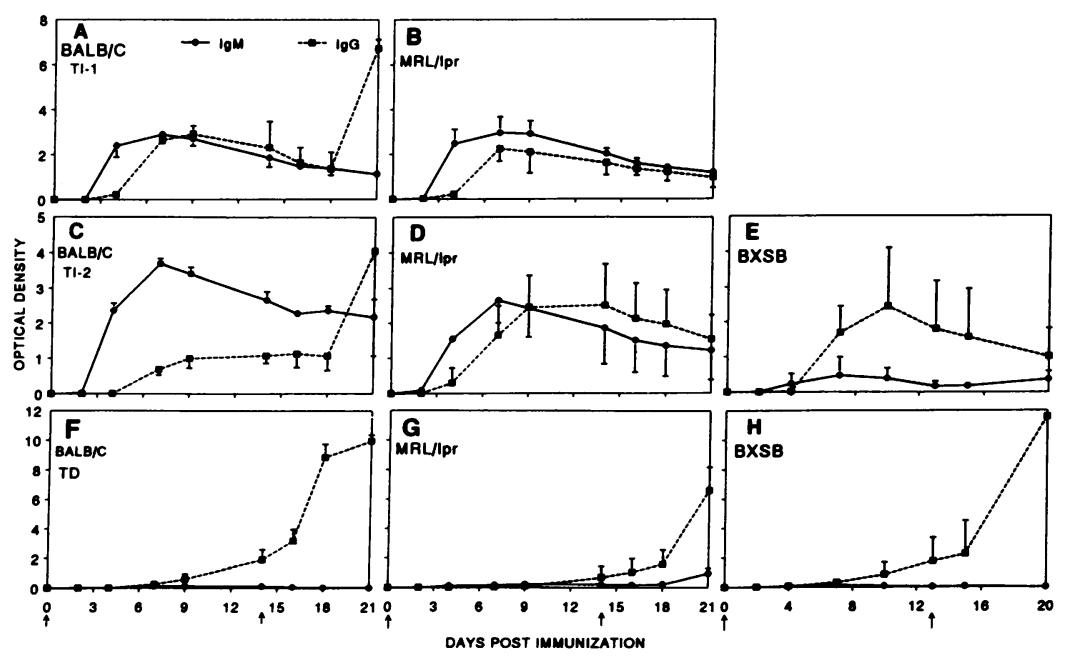

Figure 8. Time course of IgM and IgG anti-TNP antibody production. Anti-TNP reactivity after intraperitoneal injection of $100 \mu \mathrm{g}$ TNP-LPS in $100 \mu \mathrm{l}$ normal saline ( $A$ and $B$ ); i.p. injection of $100 \mu \mathrm{g}$ $\mathrm{TNP}_{50}$-Ficoll in $100 \mu \mathrm{l}$ normal saline $(C, D$, and $E)$; or subcutaneous injection of $100 \mu \mathrm{g} \mathrm{TNP}{ }_{23}-\mathrm{KLH}$ in $200 \mu \mathrm{l} \mathrm{CFA}(F, G$, and $H)$. All mice were boosted with s.c. injection of $100 \mu \mathrm{g} \mathrm{TNP}_{23}-\mathrm{KLH}$ in $200 \mu \mathrm{l}$ incomplete Freund's adjuvant on day 14 (arrows on bottom $x$ axis $)$. Control mice BALB/c $(A, C$, and $F)$ and autoimmune MRL-lpr $(B, D$, and $G)$ and BXSB $(E$ and $H)$. 
The autoimmune processes in these mice were not totally random, since every individual made an IgG autoimmune response to chromatin, usually initially directed against the (H2A-H2B)-DNA subnucleosome structure. In some cases, the quaternary interaction of $\mathrm{H} 2 \mathrm{~A}, \mathrm{H} 2 \mathrm{~B}$, and DNA was necessary to form a reactive epitope, since the individual components were unreactive. In animals without anti-dsDNA reactivity, antibodies to both the trypsin-sensitive and the trypsin-resistant regions of chromatin were also present, since trypsinization reduced but never eliminated the antichromatin reactivity. The reduction in reactivity was not caused by less substrate binding to the ELISA plate (20). With the Western blot technique, trypsinized histones were unreactive ( 5 ), probably because only epitopes on individual denatured histones were measured. As the immune response progressed, antibodies to $\mathrm{H} 1$, native DNA and the ( $\mathrm{H} 3-\mathrm{H} 4)$-DNA subnucleosome became apparent. Thus, antibodies reacting with multiple epitopes on chromatin, some requiring native antigen, were found. In previous studies, the presence of autoantibodies reactive with a number of different epitopes on the La/SS-B particle (36), RNP (37), and histidyl transfer RNA synthetase (38) have been interpreted as evidence for immunization with self antigen. The predominant reactivity of autoantibodies to conformational epitopes $(39,40)$ has also indicated autoimmunization.

It is unlikely that the pattern of reactivity that we have observed in these mice is caused by artifacts in the assays. We have previously shown that nearly equal amounts of protein and DNA are bound to the ELISA plate for all the antigens (20), that soluble and solid-phase chromatin are antigenically similar (2), and that there is a lack of assay bias as demonstrated by the reciprocal binding patterns found in patients with lupus induced by different drugs (2). In addition, the increased reactivity of some sera for (H2A-H2B)-DNA compared to $\mathrm{H} 2 \mathrm{~A}-\mathrm{H} 2 \mathrm{~B}$ is not caused by antibody valency, demonstrating that a fortuitous spacing of $\mathrm{H} 2 \mathrm{~A}-\mathrm{H} 2 \mathrm{~B}$ along DNA is not the cause of stronger reactivity with that antigen (29). We further demonstrated that equal amounts of different antibodies yielded similar ODs on their respective substrates, demonstrating that the sensitivity of binding to the various substrates is balanced. These findings support the validity of comparing serum reactivity on the different substrates.

Predominant reactivity to the (H2A-H2B)-DNA subnucleosome structure early in the murine autoimmune response is similar to that found in patients with procainamide-induced lupus (2) and in a subset of patients with SLE (reference 41 and unpublished observations). Additionally, as was found in the mice, sera from SLE patients with anti-dsDNA antibodies displayed reactivity to the ( $\mathrm{H} 3-\mathrm{H} 4)_{2}$-DNA subnucleosome after their dsDNA reactivity was removed (reference 41 and unpublished observations). Thus, there is a strong similarity in the epitopes recognized by both human and murine antichromatin autoantibodies.

Two novel aspects of the present work were the collection of serial serum samples over short time intervals and the measurement of antibody reactivity to a number of related antigens on chromatin. Once an autoimmune response started, the antibody titer typically rose to a peak within a few weeks, similar to the kinetics seen during an immunization. In a given mouse serum, IgG antibodies usually arose before or concomitantly with IgM antibodies of the same specificity. This phenomenon has also been noted with anti-Sm autoantibodies in MRL-lpr mice (42), and most likely indicates that the IgM to IgG switch is taking place rapidly, before serum IgM can be detected. A primary IgG response has also been noted in murine graft versus host disease, and has been attributed to the large amounts of cytokines produced in this system (reviewed in reference 43). It is possible that similar cytokines are produced at the site of antichromatin autoantibody production in MRL-lpr and BXSB mice, since their primary autoantibodies are often IgG. Different types of immunization can also influence the relative IgM and IgG production. Immunization with a high dose $(1,000 \mu \mathrm{g})$ rather than a medium dose $(100 \mu)$ of antigen in the absence of an adjuvant containing bacteria favored IgG over IgM production (44), as did the use of adjuvants other than CFA (45). In the present work, even immunization in CFA did not cause high IgM anti-TNP production. Thus, the lack of an observable switch from IgM to IgG reactivity can happen with certain types of immunizations.

Our data are not supportive of polyclonal activation causing most of the antichromatin autoantibodies. In BXSB mice, polyclonal activation could have caused IgM autoantibodies, since a number of different reactivities changed simultaneously, and linear regression analysis and two-sided $t$ tests confirmed their interrelatedness. However, the IgM antibodies of the MRL-lpr mice and the IgG antibodies from both strains did not display linked changes. Polyclonal IgM and specific IgG responses have been noted previously (11). Since the serum IgM antibodies in the BXSB mice often appeared after the $\mathrm{IgG}$ antibodies, their induction may not affect $\mathrm{IgG}$ production and is consistent with earlier work demonstrating that polyclonal stimulation of B cells could not by itself induce pathogenic autoantibodies (46).

For most of the serial IgM and IgG reactivities measured in this study, the antibody binding rapidly reached a peak and then gradually decreased without displaying other prominent peaks. Natural antiidiotypic antibodies (13) and antibodies induced by immunization with anti-I-J, which is thought to disrupt an idiotypic network (47), both displayed periodic fluctuations in titer. Thus, the relatively smooth change of autoantibody reactivity over time was not characteristic of a natural or a disrupted idiotypic network.

It has been proposed that bacterial DNA or ssDNA could be the initial stimuli inducing anti-dsDNA antibodies crossreactive with self material (10). However, in MRL-lpr mice, the subclass distribution of antichromatin and antidsDNA were the same, while that for anti-ssDNA was different, implying that different immunological forces were driving the dsDNA and ssDNA responses. Additionally, the observations in both strains that antichromatin antibodies invariably arose before anti-dsDNA antibodies in murine lupus, that ssDNA could not adsorb the majority of anti-dsDNA antibodies while whole chromatin could, and that adsorption with DNA could not remove the majority of chromatin-reactive antibodies argue instead in favor of a role for chromatin as the initial immunogenic stimulus inducing anti-dsDNA antibodies. Anti-dsDNA antibodies seem to be a subset of the wide spectrum of antichromatin autoantibodies present in these mice.

The results presented here compliment other studies that examined the immunologic processes responsible for autoantibody induction. Panels of anti-DNA and antichromatin monoclonal antibodies from autoimmune mice displayed hallmarks of antigen driven, though not necessarily autoantigen driven, 
immune responses such as clonotypic convergence upon switching to IgG and confinement of productive mutations to the complementarity determining regions $(48,49)$. Affinity maturation of anti-Jo-1 autoantibodies (40) and decreased reactivity of human Ro/SS-A autoantibodies with antigens from animals further from humans on the evolutionary tree (8) have been presented as additional evidence for an autoantigendriven autoimmune response.

Autoimmunization with self antigen presents a problem as a mechanism for autoantibody production, since it has been well documented that experimental immunization with self antigens in general, and chromatin (50), dsDNA (51), and histones (52) in particular, rarely induces autoantibodies, suggesting that tolerance to these molecules is firmly established in normal individuals. Maintenance of adult tolerance may be an active process involving self antigen, lymphokines, and the cells responding to them (53-55). In transgenic models of autoimmunity, it appears that $B$ cells can be deleted at an early stage of their ontogeny by being exposed to a polymeric form of antigen (56), and anergized at later stages by soluble antigen (57). The loss of one or both of these tolerance-maintaining pathways could allow abnormal expression of self-reacting Ig molecules on the B cell surface. Because antibodies reactive with many epitopes on chromatin were found in these mice, this antigen must have been involved in their induction, and because IgG2a and IgG2b were the predominant subclasses of antichromatin autoantibodies, there must also have been $T$ cell help. We propose that nontolerant B cells were exposed to an immunogenic or particulate form of chromatin that crosslinked specific surface immunoglobulins, starting the activation of the B cell and allowing subsequent internalization and processing of antigen. A defect in the catabolism of chromatin released from dying cells could lead to the presence of polymeric forms of chromatin that normally would not be exposed to the immune system, allowing the B cell to present a peptide to which the $\mathrm{T}$ cells were never tolerized. Alternatively, presentation by a nontolerant B cell of either higher than normal levels or abnormal forms of peptides from this antigen could stimulate $T$ cells. It has been demonstrated in chimeric mice that only B cells with the lpr gene or the Y chromosome associated abnormality from BXSB mice produce autoantibodies, while B cells without these defects do not $(58,59)$. Thus, one of the basic immunological defects could be at the level of the antigen presenting cell, in these cases the B cell. Studies characterizing MHC peptides, as have been achieved recently in other model systems $(60,61)$, will further clarify the antigenic structure(s) involved in systemic autoimmunity and indicate the way by which tolerance to these molecules is circumvented.

\section{Acknowledgments}

This is publication number 7421-IMM from The Scripps Research Institute (La Jolla, CA). The work reported herein was supported in part by grants AR31203, AR39555, AG-00080, and AR-34358 from the National Institutes of Health.

\section{References}

1. Schwartz, R. S., and B. D. Stollar. 1985. Origins of anti-DNA autoantibodies. J. Clin. Invest. 75:321-327.

2. Burlingame, R. W., and R. L. Rubin. 1991. Drug-induced anti-histone autoantibodies display two patterns of reactivity with substructures of chromatin. J. Clin. Invest. 88:680-690.
3. Rubin, R. L. 1992. Anti-histone antibodies. In Systemic Lupus Erythematosus. 2nd edition. R. G. Lahita, editor. John Wiley \& Sons, Inc., New York. 247-271.

4. Theofilopoulos, A. N., and F. J. Dixon. 1985. Murine models of systemic lupus erythematosus. Adv. Immunol. 37:269-390.

5. Portanova, J. P., R. E. Arndt, and B. L. Kotzin. 1988. Selective production of autoantibodies in graft-vs-host-induced and spontaneous murine lupus: predominant reactivity with histone regions accessible in chromatin. J. Immunol. 140:755-760.

6. Costa, O., and J. C. Monier. 1986. Antihistone antibodies detected by micro-ELISA and immunoblotting in mice with lupus-like syndrome (MRL/1, $\mathrm{MRL} / \mathrm{n}, \mathrm{PN}$, and NZB strains). Clin. Immunol. Immunopathol. 40:276-282.

7. Fisher, C. L., R. A. Eisenberg, and P. L. Cohen. 1988. Quantitation and IgG subclass distribution of antichromatin autoantibodies in SLE mice. Clin. Immunol. Immunopathol. 46:205-213.

8. Reichlin, M., and M. W. Reichlin. 1989. Autoantibodies to the Ro/SS-A particle react preferentially with the human antigen. J. Autoimmun. 2:359-365.

9. Diamond, B., and M. D. Scharff. 1984. Somatic mutation of the T15 heavy chain gives rise to an antibody with autoantibody specificity. Proc. Natl. Acad. Sci. USA. 81:5841-5844.

10. Pisetsky, D. S., J. P. Grudier, and G. S. Gilkeson. 1990. A role for immunogenic DNA in the pathogenesis of systemic lupus erythematosus. Arthritis Rheum. 33:153-159.

11. Klinman, D. M., R. A. Eisenberg, and A. D. Steinberg. 1990. Development of the autoimmune B cell repertoire in MRL-lpr/lpr mice. J. Immunol. 144:506-511.

12. Harkiss, G. D., and B. H. Hahn. 1990. The characterization of DNA antibody idiotypes: a discussion. J. Autoimmun. 3:367-375.

13. Varela, F., A. Andersson, G. Dietrich, A. Sundblad, D. Holmberg, M. Kazatchkine, and A. Coutinho. 1991. Population dynamics of natural antibodies in normal and autoimmune individuals. Proc. Natl. Acad. Sci. USA. 88:59175921.

14. Isenberg, D., et al. 1990. Comparison of DNA antibody idiotypes in human sera: an international colaborative study of 19 idiotypes from 11 different laboratories. J. Autoimmun. 3:393-414.

15. Andrews, B. S., R. A. Eisenberg, A. N. Theofilopoulos, S. Izui, C. B. Wilson, P. J. McConahey, E. D. Murphy, J. B. Roths, and F. J. Dixon. 1978. Spontaneous Murine lupus-like syndromes: clinical and immunopathological manifestations in several strains. J. Exp. Med. 148:1 198-1215.

16. Godfrey, J. E., A. D. Baxevanis, and E. N. Moudrianakis. 1990. Spectropolarimetric analysis of the core histone octamer and its subunits. Biochemistry. 29:965-972.

17. Mencke, A. J., and R. L. Rill. 1982. Circular dichroism and thermal denaturation studies of subnucleosomes and their relationships to nucleosome structure. Biochemistry. 21:4362-4370.

18. Arents, G., R. W. Burlingame, B.-C. Wang, W. E. Love, and E. N. Moudrianakis. 1991. The nucleosomal core histone octamer at 3.1 A resolution: a tripartite protein assembly and a left-handed superhelix. Proc. Natl. Acad. Sci. USA. 88:10148-10152.

19. Richmond, T. J., J. T. Finch, B. Rushton, D. Rhodes, and A. Klug. 1984. Structure of the nucleosome core particle at 7A resolution. Nature (Lond.). 311:532-537.

20. Burlingame, R. W., and R. L. Rubin. 1990. Subnucleosome structures as substrates in enzyme-linked immunosorbent assays. J. Immunol. Methods. 134:187-199.

21. Oohara, I., and A. Wada. 1987. Spectroscopic studies on histone-DNA interactions $I$. The interaction of histone (H2A,H2B) dimer with DNA: DNA sequence dependence. J. Mol. Biol. 196:389-397.

22. van der Westhuyzen, D. R., and C. Von Holt. 1971. A new procedure for the isolation and fractionation of histones. FEBS(Fed. Eur. Biochem. Soc.) Lett. 14:333-337.

23. Lutter, L. C. 1978. Kinetic analysis of deoxyribonuclease I cleavages in the nucleosome core: evidence for a DNA superhelix. J. Mol. Biol. 124:391-420.

24. Weintraub, H., and F. Van Lente. 1974. Dissection of chromosome structure with trypsin and nucleases. Proc. Natl. Acad. Sci. USA. 71:4249-4253.

25. Rubin, R. L., and A. N. Theofilopoulos. 1988. Monoclonal Autoantibodies reacting with multiple structurally related and unrelated macromolecules. Int. Rev. Immunol. 3:71-95.

26. Rittenberg, M. B., and A. A. Amkraut. 1966. Immunogenicity of trinitrophenyl-hemocyanin. Production of primary and secondary antihapten responses. J. Immunol. 97:421-430.

27. Weintraub, H. 1985. High-resolution mapping of S1- and DNase I-hypersensitive sites in chromatin. Mol. Cell. Biol. 5:1538-1539.

28. Faiferman, I., and D. Koffler. 1987. Reaction of antipolynucleotide antibody from systemic lupus erythematosus patient serum with double-stranded DNA complexed to protein. Arthritis Rheum. 30:814-818.

29. Rubin, R. L., S. A. Bell, and R. W. Burlingame. 1992. Autoantibodies associated with lupus induced by diverse drugs target a similar epitope in the (H2A-H2B)-DNA complex. J. Clin. Invest. 90:165-173.

30. Papalian, M., E. Lafer, R. Wong, and B. D. Stollar. 1980. Reaction of 
systemic lupus erythematosus antinative DNA antibodies with native DNA fragments from 20 to 1,200 base pairs. J. Clin. Invest. 65:469-477.

31. Prud'homme, G. J., C. L. Park, T. M. Fieser, R. Kofler, F. L. Dixon, and A. N. Theofilopoulos. 1983. Identification of a B cell differentiation factor(s) spontaneously produced by proliferating $\mathrm{T}$ cells in murine lupus strains of the lpr/lpr genotype. J. Exp. Med. 157:730-742.

32. Cohen, P. L., E. W. Shores, R. Rapoport, S. Caster, R. A. Eisenberg, and D. S. Pisetsky. 1985. Anti-Sm autoantibodies in MRL mice: analysis of precursor frequency. Cell. Immunol. 96:448-454.

33. Esser, C., and A. Radbruch. 1990. Immunoglobulin class switching: molecular and cellular analysis. Annu. Rev. Immunol. 8:717-735.

34. French, D. L., R. Laskov, and M. D. Scharff. 1989. The role of somatic hypermutation in the generation of antibody diversity. Science (Wash. DC). 244:1152-1157.

35. Matis, L. A. 1990. The molecular basis of T-cell specificity. Annu. Rev. Immunol. 8:65-82.

36. St. Clair, E. W., J. A. Burch, Jr., M. M. Ward, J. D. Keene, and D. S. Pisetsky. 1990. Temporal correlation of antibody responses to different epitopes of the human La autoantigen. J. Clin. Invest. 85:515-521.

37. Habets, W. J., M. H. Hoet, and W. J. van Venrooij. 1990. Epitope patterns of anti-RNP antibodies in rheumatic diseases. Evidence for an antigen-driven autoimmune response. Arthritis Rheum. 33:834-841.

38. Miller, F. W., S. A. Twitty, T. Biswas, and P. H. Plotz. 1990. Origin and regulation of a disease-specific autoantibody response. J. Clin. Invest. 85:468475.

39. Boire, G., F.-J. Lopez-Longo, S. Lapointe, and H. A. Menard. 1991. Sera from patients with autoimmune disease recognize conformational determinants on the 60-kd Ro/SS-A protein. Arthritis Rheum. 34:722-730.

40. Miller, F. W., K. A. Waite, T. Biswas, and P. H. Plotz. 1990. The role of an autoantigen, histidyl-tRNA synthetase, in the induction and maintenance of autoimmunity. Proc. Natl. Acad. Sci. USA. 87:9933-9937.

41. Burlingame, R. W., E. M. Tan, and R. L. Rubin. 1990. The central role of chromatin in autoimmune responses to histones and DNA in systemic lupus erythematosus. Arthritis Rheum. 33(Suppl.):S100.

42. Eisenberg, R. A., S. Y. Craven, and P. L. Cohen. 1987. Isotype progression and clonality of anti-Sm autoantibodies in MRL/Mp-lpr/lpr mice. J. Immunol. 139:728-733.

43. Gleichmann, E., S. T. Pals, A. G. Rolink, T. Radaszkiewicz, and H. Gleichmann. 1984. Graft-versus-host reactions: clues to the etiopathology of a spectrum of immunological diseases. Immunol. Today. 5:324-332.

44. Torrigiani, G. 1971. Quantitative estimation of antibodies in the immunoglobulin classes of the mouse. 1. Effect of adjuvants on the antibody response to human serum albumin and keyhole limpet haemocyanin. Clin. Exp. Immunol. 11:125-135.

45. Kenney, J. S., B. W. Hughes, M. P. Masada, and A. C. Allison. 1989. Influence of adjuvants on the quantity, affinity, isotype and epitope specificity of murine antibodies. J. Immunol. Methods. 121:157-166.

46. Hang L. M., M. T. Aguado, F. J. Dixon, and A. N. Theofilopoulos. 1985. Induction of severe autoimmune disease in normal mice by simultaneous action of multiple immunostimulators. J. Exp. Med. 161:423-428.
47. Shefner, R., G. Kleiner, A. Turken, L. Papazian, and B. Diamond. 1991. A novel class of anti-DNA antibodies identified in BALB/c mice. J. Exp. Med. 173:287-296.

48. Shlomchik, M., M. Mascelli, H. Shan, M. Z. Radic, D. Pisetsky, A. Marshak-Rothstein, and M. Weigert. 1990. Anti-DNA antibodies from autoimmune mice arise by clonal expansion and somatic mutation. J. Exp. Med. 171:265297.

49. Losman, M. J., T. M. Fasy, K. E. Novick, and M. Monestier. 1992. Monoclonal autoantibodies to subnucleosomes from a MRL/Mp-++ mouse. $J$ Immunol. 148:1561-1569.

50. Tahourdin, C. S. M., and M. Bustin. 1980. Chromatin subunits elicit species-specific antibodies against nucleoprotein antigenic determinants. Biochemistry. 19:4387-4394.

51. Madaio, M. P., S. Hodder, R. S. Schwartz, and B. D. Stollar. 1984. Responsiveness of autoimmune and normal mice to nucleic acid antigens. J. Immunol. 132:872-876.

52. Rubin, R. L., F-L. Tang, G. Tsay, and K. M. Pollard. 1990. Pseudoautoimmunity in normal mice: Anti-histone antibodies elicited by immunization versus induction during graft-versus-host reaction. Clin. Immunol. Immuno pathol. 54:320-332.

53. Nossal, G. J. V. 1989. Immunologic tolerance: collaboration between antigen and lymphokines. Science (Wash. DC). 245:147-153.

54. Gahring, L. C., and W. O. Weigle. 1990. The regulatory effects of cytokines on the induction of a peripheral immunologic tolerance in mice. J. Im munol. 145:1318-1323.

55. Dintzis, H. M., and R. Z. Dintzis. 1988. A molecular basis for immune regulation: the immunon hypothesis. In Theoretical Immunology, Part One, SF Studies in the Sciences of Complexity. A. S. Perelson, editor. Addison-Wesley Publishing Company, Reading, MA. p. 83-103.

56. Hartley, S. B., J. Crosbie, R. Brink, A. B. Kantor, A. Basten, and C. C. Goodnow. 1991. Elimination from peripheral lymphoid tissues of self-reactive B lymphocytes recognizing membrane-bound antigens. Nature (Lond.). 353:765769.

57. Goodnow, C. C., J. Crosbie, H. Jorgensen, R. A. Brink, and A. Basten. 1989. Induction of self-tolerance in mature peripheral B lymphocytes. Nature (Lond.). 342:385-391.

58. Sobel, E. S., T. Katagiri, K. Katagiri, S. C. Morris, P. L. Cohen, and R. A Eisenberg. 1991. An intrinsic B cell defect is required for the production of autoantibodies in the $l p r$ model of murine systemic autoimmunity. J. Exp. Med. 173:1441-1449.

59. Merino, R., L. Fossati, M. Lacour, and S. Izui. 1991. Selective autoantibody production by $\mathrm{Yaa}^{+} \mathrm{B}$ cells in autoimmune $\mathrm{Yaa}^{+}-\mathrm{Yaa}^{-}$bone marrow chimeric mice. J. Exp. Med. 174:1023-1029.

60. Jardetzky, T. S., W. S. Lane, R. A. Robinson, D. R. Madden, and D. C. Wiley. 1991. Identification of self peptides bound to purified HLA-B27. Nature (Lond.). 353:326-329.

61. Hunt, D. F., H. Michael, T. A. Dickinson, J. Shabanowitz, A. L. Cox, K. Sakaguchi, E. Appella, H. M. Grey, and A. Sette. 1992. Peptides presented to the immune system by the murine class II major histocompatibility complex molecule I-A d. Science (Wash. DC). 256:1817-1820 